\title{
ULTRASTRUCTURE AND FUNCTION OF MITOCHONDRIA in Gametocytic stage of Plasmodium falciparum
}

\author{
KRUNGKRAI J.*, PRAPUNWATTANA P.* \& KRUNGKRAI S.R.**
}

\section{Summary :}

Morphological properties of the mitochondrial organelles in the asexual and sexual gametocytic stages of Plasmodium falciparum have been analyzed and found to be markedly different. From in vitro cultures of both stages in human erythrocytes, it has been demonstrated that the asexual stages contained a defined doublemembrane organelle having a few tubular-like cristae. The numbers of mitochondria in the gametocytes were found to be $\sim 6$ organelles per parasite, and they showed a greater density of the cristae than that of the asexual stage parasite. The organelles of the gametocytes were successfully purified by differential centrifugation following Percoll density gradient separation with the results of $\sim 7 \%$ yields and $\sim 5$ folds. The gametocytic organelles contained much more activities of mitochondrial electron transporting enzymes (i.e., cytochrome c reductase, cytochrome c oxidase) than the asexual stage organelles. Mitochondrial function as measured by oxygen consumption were found to be different between these two stages organelles. Their rates of oxygen consumption were relatively low, as compared to those of human leukocyte and mouse liver mitochondria. In contrast to the coupled mammalian mitochondria, the gametocytic organelles were in the uncoupling state between oxidation and phosphorylation reactions during their respiration. However, they were sensitive to inhibitors of the electron transport system, e.g., antimycin A, cyanide. Our results suggest that the mitochondria of the gametocytic stages are metabolically active and still underdeveloped, although their inner membranes are extensively folded. The biochemical significance of the unique structure of the mitochondria in these developing stages in host erythrocytes remains to be elucidated.

KEY WORDS : Plasmodium falciparum, gametocyte, mitochondria, electron transport system, oxygen consumption.
Résumé : UlTRASTRUCTURE ET FONCTION DES MITOCHONDRIES AU STADE GAMÉTOCYTE DE PLASMODIUM FALCIPARUM

Les morphologies et les propriétés des organelles mitochondriales des stades asexués et sexués (gamétocytes) de P. falciparum, maintenu in vitro sur érythrocytes humains, ont été analysées. Le stade asexué (trophozoïte) contient une organelle à double membrane possédant peu de crêtes de type "tubulaire". Les gamétocytes possèdent par contre un plus grand nombre d'organelles mitochondriales présentant une plus grande densité de crêtes. Les organelles mitochondriales des gamétocytes ont été purifiées par centrifugation différentielle suivie d'une séparation sur gradient de densité de Percoll avec un rendement de $7 \%$ et un facteur de purification de cinq. Les organelles gamétocytaires présentent des activités enzymatiques liées au transport des électrons (cytochrome c réductase, cytochrome c oxydase) plus important que les organelles du stade asexué. Des différences de consommations d'oxygène sont également observées entre ces organelles qui restent néanmoins relativement faibles comparées à celles des mitochondries des leucocytes humains et des cellules hépatiques de souris. Contrairement aux mitochondries des Mammifères qui sont dans un état couplé, les organelles gamétocytaires sont découplées entre des réactions d'oxydation et de phosphorylation. Cependant, elles sont sensibles aux inhibiteurs du transport des électrons (antimycin A, cyanide). Nos résultats suggèrent que les mitochondries des gamétocytes sont métaboliquement actives et encore sous-développées bien que leurs membranes internes présentent de nombreuses crêtes. La signification biochimique de la structure unique des mitochondries à ces stades de développement dans les hématies humaines reste à élucider

MOTS CLÉS : Plasmodium falciparum, gamétocyte, mitochondrie, système de transport d'électrons, consommation d'oxygène.

\section{INTRODUCTION}

T The human malarial parasite Plasmodium falciparum contains at least two developmental stages, i.e., asexual blood parasite and sexual gametocyte, during multiplication in the host erythrocytes. Differentiation of the asexual blood stage into

\footnotetext{
* Department of Biochemistry, Faculty of Medicine, Chulalongkorn University, Rama IV Road, Bangkok 10330, Thailand.

** Department of Biochemistry, Faculty of Science, Rangsit University, Patumthani 12000, Thailand.

Correspondence: Jerapan Krungkrai.

Tel.: (662)-2564482 - Fax: (662)-2524986

Email: fmedjkk@md2.md.chula.ac.th
}

the gametocytic stage exhibits a series of complicated process, e.g., formation of microtubule, DNA, RNA and protein synthesis, energy metabolism, signal transduction, etc., which are essential for continued growth and survival of the parasite (Sinden \& Smalley, 1979; Alano \& Carter, 1990; Lobo \& Kumar, 1998). Several lines of evidence on morphological, ultrastructural and genetic analyses of the mitochondria in $P$. falciparum suggest that the organelle may be functionally regulated during differentiation in the human host (Aikawa et al., 1966; Aikawa, 1971; Langreth et al., 1978; Fry \& Beesley, 1991; Feagin \& Drew, 1995; Petmitr \& Krungkrai, 1995; Learngaramkul et al., 1999).

The morphological properties of the mitochondria in the asexual blood stages and gametocytes of $P$. falci- 
parum have been shown to be stage-dependent variations, based on the transmission electron microscopic technique (Aikawa et al., 1966; Aikawa, 1971; Langreth et al., 1978; Sinden, 1982; Fry \& Beesley, 1991; Krungkrai et al., 1993; Krungkrai, 1995; Krungkrai et al., 1999; Learngaramkul et al., 1999). Either acristate or a few tubular-like cristate mitochondrion has been demonstrated in the asexual blood stage-parasite, whereas the organelle with great numbers of the cristate structure has been associated to the sexual blood stage-parasite. Until recently, only the organelles in the asexual blood stage-parasite have been isolated, they are typically double-membranes organelles but do not have cristae, and have been found to be metabolically active (Fry \& Beesley, 1991; Krungkrai et al., 1993; Krungkrai, 1995; Learngaramkul et al., 1999). The biochemical functions of mitochondria in the sexual stages during gametocytogenesis has been less well studied, nevertheless, the role of mitochondria during the asexual intraerythrocytic stage of the $P$. falciparum life cycle is still unclear. It is proposed that in malarial parasites the mitochondrial electron transport chain may function as electron sink in the pyrimidine biosynthetic pathway via dihydroorotate dehydrogenase, which is the mitochondrial enzyme and linked to the electron transport chain through ubiquinone (Gutteridge et al., 1979; Krungkrai et al., 1991; Krungkrai, 1995). Many antimalarial drugs have been known to act specifically on the mitochondria, e.g., tetracycline (Prapunwatana et al., 1988), primaquine (Lanners, 1991; Vaidya et al., 1993), atovaquone (Fry \& Pudney 1992; Krungkrai et al., 1997; Srivastava et al., 1997), artemether (Kawa et al., 1993). The evidence on the action of the antimalarial drugs further support that the mitochondrion is a novel chemotherapeutic target for drug development.

We report here for the first time that the ultrastructural and biochemical characterization have been carried out in the mitochondrial organelles purified from the sexual gametocytic stage, compared to the asexual blood stage of $P$. falciparum.

\section{MATERIALS AND METHODS}

\section{MALARIAL PARASITES}

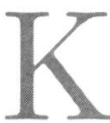
T3 isolate of $P$. falciparum was taken from a Thai patient's blood in Kanchanaburi province, western Thailand, in 1994. The parasite was kept in the sorbitol-glycerol cryoprotectant (Trigg, 1978), and frequently thawed for in vitro cultivation by using the candle jar method of Trager \& Jensen (1976). The cultures were continuously induced for production of the sexual blood stages; after one-year cultivation the sexual stage-parasites were still pro- duced and served as a gametocyte-producing line. In order to get mainly trophozoites, a representative of the asexual stage, the culture was treated by the sorbitol procedure of Lambros \& Vanderberg (1979). For the sexual blood stages, the culture was induced according to Ifediba \& Vanderberg (1981). About 3-4\% parasitemia of mixed sexual blood stages was routinely obtained on $\sim 10-15$-day cultivation without the addition of normal fresh erythrocytes into their cultures. The sexual stages, mostly stages III and IV of development according to classification of Hawking et al. (1971), were purified by the Percoll step-wise gradient centrifugation method of Knight \& Sinden (1982). The asexual trophozoite stage and the sexual gametocyte stages III and IV used in this study were very active in their macromolecules biosynthesis (Sinden \& Smalley, 1979; Inselburg \& Banyal, 1984; De Rojas \& Wasserman, 1985). The parasites were freed from their host erythrocytes by incubating in an equal volume of $0.15 \%$ and $0.05 \%$ saponin for asexual and sexual stages, respectively, in RPMI 1640 medium at $37^{\circ} \mathrm{C}$ for $20 \mathrm{~min}$. The host cell-free parasites were then washed at least four times with the medium.

\section{ISOLATION OF MITOCHONDRIA}

Mitochondria of the host cell-free parasites harboring either the asexual or sexual stages were prepared by differential centrifugation following $22 \%$ Percoll density gradient separation as previously described (Fry \& Beesley, 1991; Krungkrai et al., 1993; Krungkrai, 1995). For the mitochondria isolation of the sexual stages, the established procedure was modified, i.e., reduced number of strokes (less than 20 times) during homogenization of parasite in an ice-cold medium (containing $75 \mathrm{mM}$ sucrose, $225 \mathrm{mM}$ mannitol, $5 \mathrm{mM} \mathrm{MgCl}_{2}$, $5 \mathrm{mM} \mathrm{KH} \mathrm{PO}_{4}, 1 \mathrm{mM}$ ethylene glycol bis( $\beta$-aminoethyl ether)-N,N,N',N'-tetraacetic acid, $5 \mathrm{mM} \mathrm{N}$-2-hydroxyethylpiperazine-N'-2-ethanesulfonic acid, $\mathrm{pH} 7.4$ ), decrease the ratio of the parasite to the homogenizing medium from 1:10 for the asexual parasites to 1:20, and omission of the Percoll step after differential centrifugation in some experiments, especially for their metabolic studies. In comparison, mammalian mitochondria were isolated from mouse liver as previously described (Rickwood et al., 1987). Human leukocytes were purified from whole blood as mononuclear cells using Ficoll-Paque separating media according to the manufacturer's instruction.

\section{OXYGEN CONSUMPTION MEASUREMENT}

The rate of oxygen consumption of the mitochondrial organelles from the asexual and sexual blood stages was measured polarographically in the homogenizing medium as described before (Krungkrai et al., 1999) by using a Clark-type oxygen electrode and YSI oxygen 
monitor according to the calibration method of Robinson \& Cooper (1970). The oxygen consumption reaction in a chamber with volume of $3 \mathrm{ml}$ was followed for 3-5 min and recorded at $37^{\circ} \mathrm{C}$ with a temperature-controlled circulator. Compounds which had effect on mammalian mitochondrial functions (Hatefi, 1985), e.g., $\mathrm{KCN}$, antimycin A, succinate, adenosine 5'diphosphate (ADP), were tested by adding to the oxygen consumption chamber, and the rate of oxygen consumption was then followed for the next 3-5 min. Respiratory rate was expressed as nmoles oxygen utilized $/ \mathrm{min} / \mathrm{mg}$ protein. ADP:O ratio was estimated according to the method of Estrabrook (1967).

\section{MiscellaneOUS METHODS}

The enzymes cytochrome c reductase (complex III) and cytochrome c oxidase (complex IV) of the mitochondrial electron transport system were assayed in the organelles isolated from both stages as described (Krungkrai et al., 1993; 1997). Transmission electron microscopy and fluorescence microscopy (rhodamine 123 staining) of the parasites from both stages and their mitochondrial organelles samples were performed as described (Krungkrai, 1995). Light microscopy was done on Giemsa stained thin smear of parasites using 100X oil immersion lens. Protein concentrations were determined by the method of Bradford (1976) and using bovine serum albumin as standard.

\section{RESULTS}

\section{MORPHOLOGICAL CHARACTERISTICS OF MITOCHONDRIA IN ASEXUAL AND SEXUAL BLOOD STAGES OF P. FALCIPARUM}

1 The induced sexual stage-parasites were purified from the asexual stages. Figure 1 shows light micrograph of the pure sexual blood stages containing mostly stages III and IV. In comparison to the sexual stages, the asexual stages, mostly trophozoite stage, were also synchronized and purified. Based on serial section of the parasites and transmission electron microscopic technique, it was reported that there were apparent variations in size and appearance of the mitochondria between the asexual and sexual stages (Krungkrai, 1995; Learngaramkul et al., 1999; Krungkrai et al., 1999). This pursued our efforts to biochemical study the mitochondrial organelles in both stages of parasite development. Figure $2 \mathrm{~A}$ shows the transmission electron micrograph of an erythrocyte-free trophozoite stage that had been prepared by treating the infected cells with $0.15 \%$ saponin. It had a single mitochondrion, described as clearly defined doublemembrane organelle. The dumbbell-like elongated structure of the observed organelle was prepared for binary fission into the next developmental stage (Fig. 2A). Closer examination on the transmission elec-

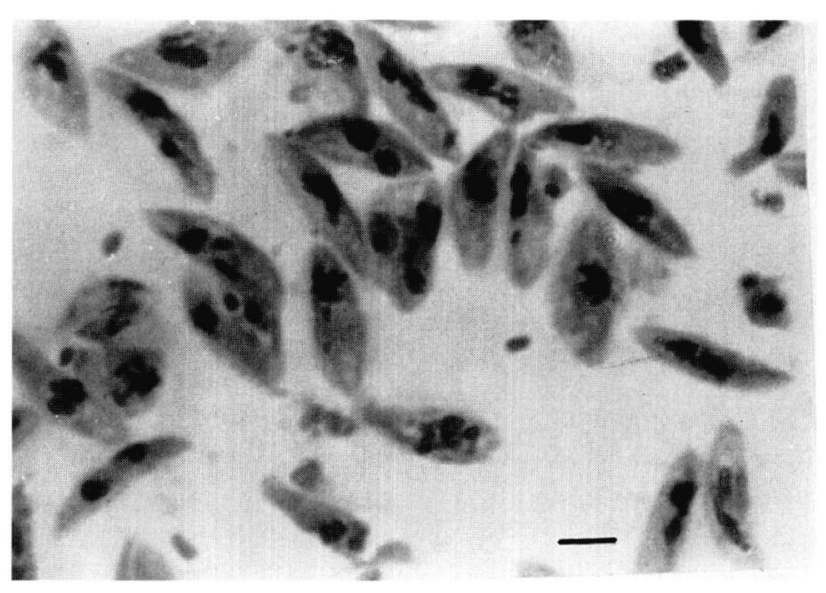

Fig. 1. - Light micrograph of purified sexual blood stage-parasites from in vitro cultures of $P$. falciparum. The parasites were stained with Giemsa and examined under light microscope. The bar represents $10 \mu \mathrm{m}$.

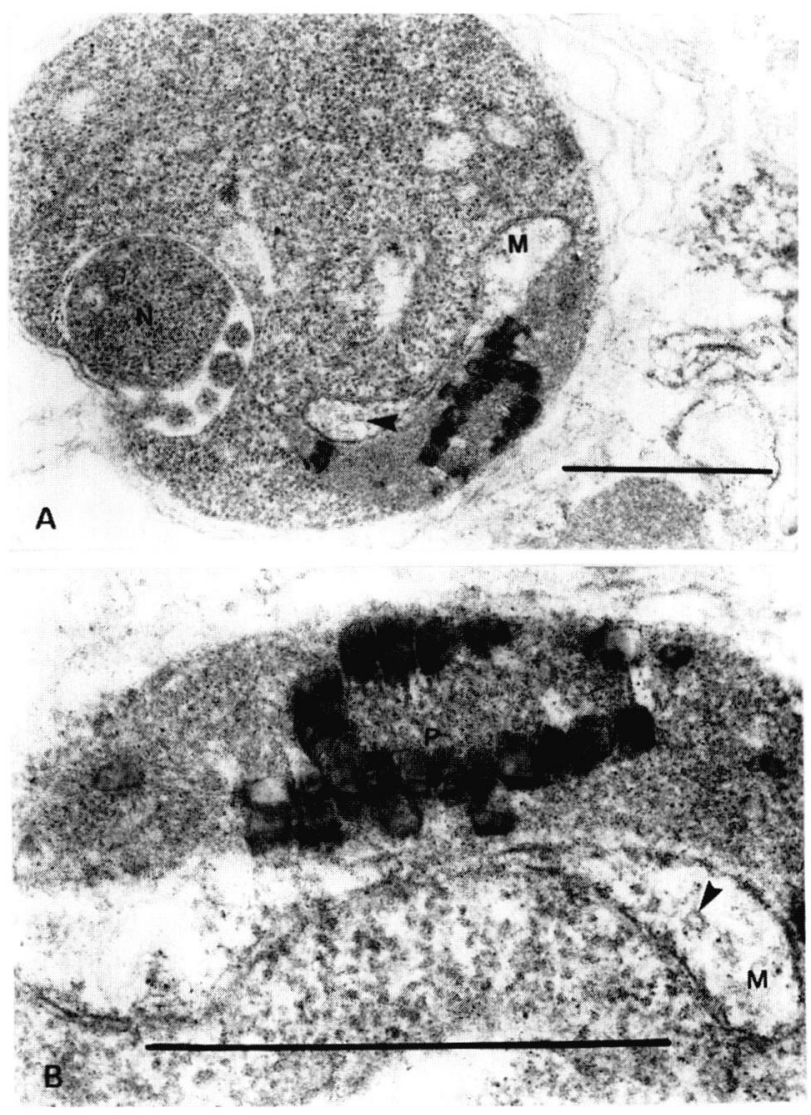

Fig. 2. - Transmission electron micrograph of the asexual trophozoite stage of $P$. falciparum. A single mitochondrion is observed with a clearly double membrane organelle, and an elongated form which is preparing for binary fission (A). It is noted that only one tubular cristae structure, marked by an arrowhead, is associated to the organelle at higher magnification (B). The bar represents $1 \mu \mathrm{m}$. N, nucleus; $\mathrm{M}$, mitochondria; $\mathrm{P}$, crystalline pigment. 
tron micrograph revealed the presence of only one tubular-like cristae in the mitochondrion of the asexual stage parasite (Fig. 2B). The marked differences of ultrastructure of the mitochondria were found between the asexual and sexual gametocytic stages. Figure $3 \mathrm{~A}$ shows a sexual stage parasite sitting in the host ery-

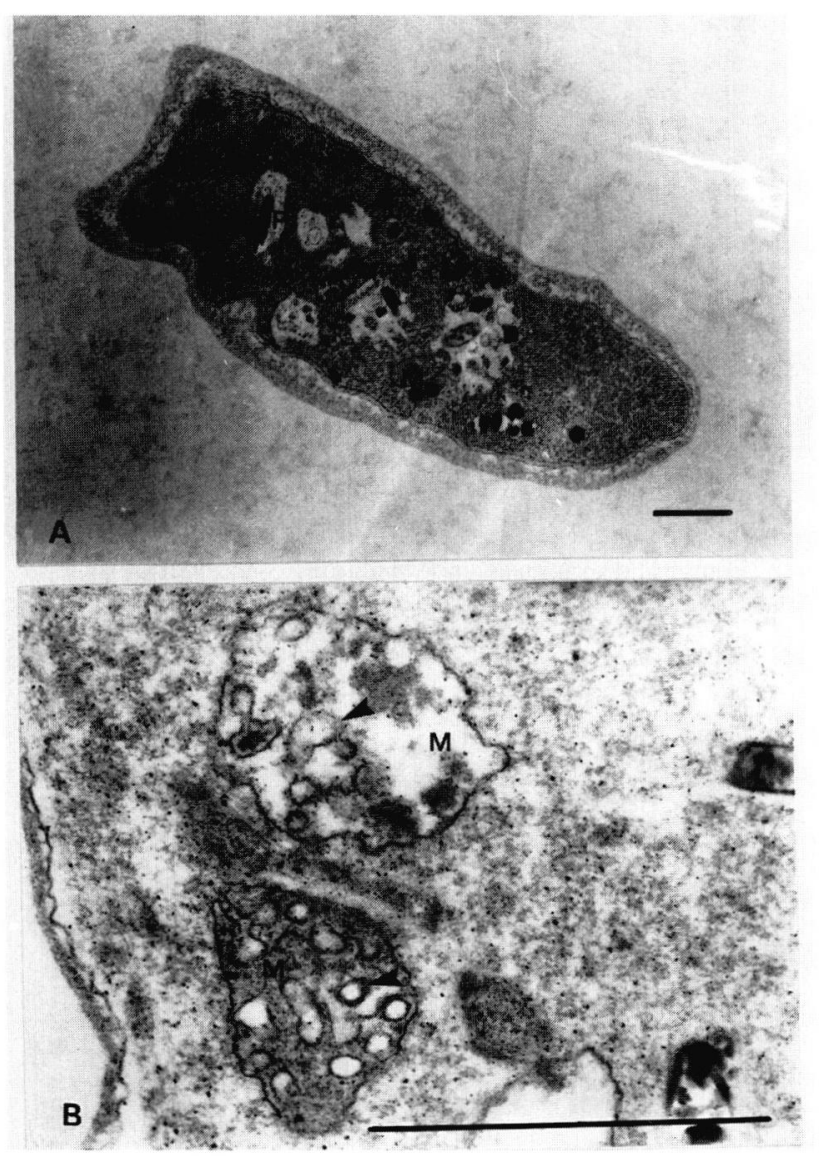

Fig. 3. - Transmission electron micrograph of the sexual blood stage of $P$. falciparum (gametocyte stage IV). Many mitochondria are observed in the single parasite (A). A higher magnification of two organelles containing numerous cristae structure (arrowhead) is shown (B). The bar represents $1 \mu \mathrm{m}$. M, mitochondria; P, crystalline pigment. throcyte. More than 50 parasites were performed to examine the cristate structure and numbers of mitochondria in both male and female gametocytes, and some parasites having $\sim 6$ organelles were made for serial sectioning. Thus the gametocytes contained $6 \pm 2$ mitochondrial organelles. It was also demonstrated that each organelle in the sexual stage contained a greater density of tubular-like cristae (Fig. 3B).

We have successfully developed a protocol to isolate the mitochondrial organelles from the asexual blood stages of both $P$. berghei (Krungkrai et al., 1993) and P. falciparum (Krungkrai, 1995). However, the established protocol could not be applied for the sexual stages of $P$. falciparum. We modified steps in the mitochondria isolation in the sexual stage-parasites. The sexual stage-infected erythrocytes were found to be sensitive to saponin treatment, in contrast, they were resistant to $5 \%$ sorbitol treatment. At $0.15 \%$ saponin, it caused deformation of mitochondria's structure as assessed by electron microscopic technique, the organelle preparation had no any biochemically active, such as oxygen consumption and rhodamine 123 accumulation. The host cell free-sexual stage parasite was more fragile than the host cell free-asexual trophozoite stage. The Percoll gradient centrifugation step of mitochondrial organelle isolated from the sexual stage resulted in low yields $(\sim 6-7 \%)$ and low folds-purification $(\sim 4-$ $5 \times)$ as determined by the marker enzymes cytochrome $\mathrm{c}$ reductase and cytochrome c oxidase (Table I). Nevertheless, the mitochondrial organelles from the sexual stages were purified and structurally intact as evidence of their maintaining high transmembrane potential by rhodamine 123 accumulation (data not shown). Contaminations of the mitochondrial preparations were those of food vacuoles containing hemozoin pigments, resealed and unidentified vacuoles, as well as free hemozoin pigment. In some preparations, the apicoplast organelle was also demonstrated (data not shown). The mitochondrial preparation contained double-membrane and tubular-like cristate organelles (Fig. 4A), as was found

\begin{tabular}{|c|c|c|c|c|c|}
\hline \multirow[b]{2}{*}{ Step } & \multirow[b]{2}{*}{$\begin{array}{c}\text { Protein } \\
(\mathrm{mg})\end{array}$} & \multicolumn{2}{|c|}{ Cytochrome c reductase } & \multicolumn{2}{|c|}{ Cytochrome c oxidase } \\
\hline & & $\begin{array}{c}\text { Activity } \\
(\mathrm{mU})\end{array}$ & $\begin{array}{l}\text { Specific } \\
\text { activity } \\
(\mathrm{mU} / \mathrm{mg})\end{array}$ & $\begin{array}{c}\text { Activity } \\
(\mathrm{mU})\end{array}$ & $\begin{array}{c}\text { Specific } \\
\text { activity } \\
(\mathrm{mU} / \mathrm{mg})\end{array}$ \\
\hline 1. Homogenate $(6 \mathrm{ml})$ & 44.9 & 93.38 & 2.08 & 106.41 & 2.37 \\
\hline 2. $4,500 \times g$ supernate & 31.4 & 56.96 & 1.81 & 69.17 & 2.20 \\
\hline 3. Crude mitochondria $(24,000 \times$ g pellet $)$ & 9.4 & 28.95 & 3.08 & 31.92 & 3.39 \\
\hline \multirow[t]{2}{*}{ 4. Pure mitochondria ( $22 \%$ Percoll gradient) } & 0.6 & 5.60 & 9.33 & 7.45 & 12.42 \\
\hline & & $(6 \%)^{\mathrm{a}}$ & $(4.5 \times)^{\mathrm{b}}$ & $(7 \%)^{\mathrm{a}}$ & $(5.2 \times)^{\mathrm{b}}$ \\
\hline
\end{tabular}

\footnotetext{
a $\%$ yield $=$ [activity $(\mathrm{mU})$ of pure mitochondria/activity of homogenate $\times 100$ for each enzyme. The $\mathrm{mU}$ is $\mathrm{nmol} / \mathrm{min}$.

b X-fold purification $=$ specific activity $(\mathrm{mU} / \mathrm{mg})$ of pure mitochondria per specific activity of homogenate.
}

Table I. - Activities of mitochondrial marker enzymes during the organelle isolation from $1.0 \mathrm{ml}\left(\sim 5 \times 10^{11}\right.$ cells $)$ of purified sexual stages of P. falciparum. 


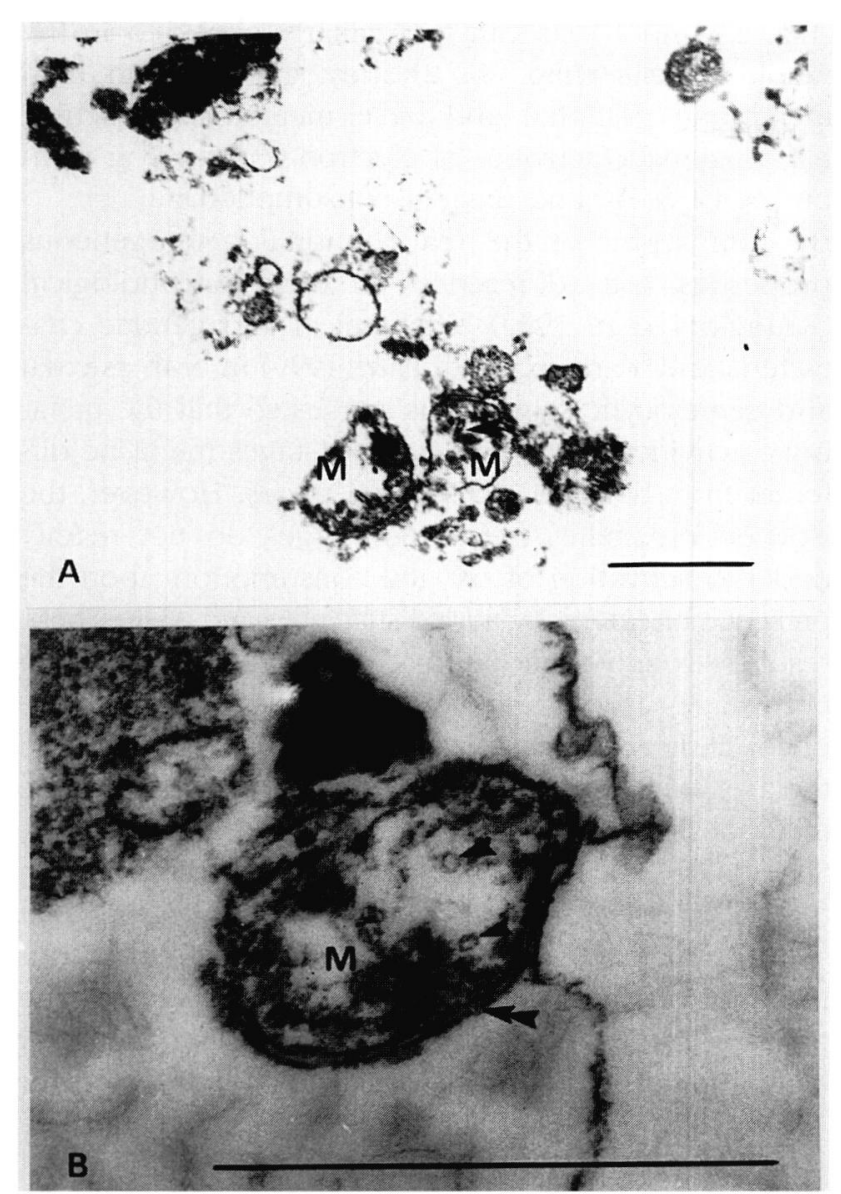

Fig. 4. - Transmission electron micrograph of the mitochondrial organelles isolated from sexual blood stage of $P$. falciparum. A. The organelles contain many tubular cristate structures (arrowhead), as was found in the organelle of the intact parasite. B. A higher magnification of an isolated organelle indicates the mitochondrion is still intact with clearly defined double membranes, marked by double arrowhead. The bar represents $1 \mu \mathrm{m}$. M, mitochondria.

in the whole cell parasite (Fig. 3). Higher magnification of the isolated organelle from the sexual stage showed a defined double-membrane structure having some cristae (Fig. 4B). The numbers of cristae in the isolated organelle were somewhat lower than those observed in the intact parasite (Fig. 3B).

\section{METABOLIC ACTIVITIES}

\section{OF MITOCHONDRIAL ORGANELLES IN ASEXUAL} AND SEXUAL BLOOD STAGES OF P. FALCIPARUM

Metabolic activities of mitochondria in the parasites isolated from both asexual (mostly trophozoite stage) and sexual stages (mostly stages III and IV) were assessed by determining the activities of electron transporting enzymes and oxygen consumption. The organelles from gametocytes contained cytochrome c reductase (complex III) and cytochrome c oxidase (complex IV) with specific activities of $10.9 \pm 3.0(n=4)$ and $13.5 \pm$ $2.4(\mathrm{n}=4) \mathrm{nmol} / \mathrm{min} / \mathrm{mg}$ protein of mitochondria, res-

\begin{tabular}{lccc}
\hline & \multicolumn{3}{c}{$\begin{array}{c}\text { Oxygen consumption } \\
\text { (nmol/min/mg protein) }\end{array}$} \\
\cline { 2 - 4 } \multicolumn{1}{c}{ Condition } & Asexual stage & Sexual stage & Mouse liver \\
\hline Control & $1.66 \pm 0.23(10)^{\mathrm{a}}$ & $0.90 \pm 0.08(6)$ & $20.18 \pm 1.5(5)$ \\
Addition & & & \\
$+3.3 \mathrm{mM} \mathrm{Succinate}$ & $1.45 \pm 0.30$ & $0.96 \pm 0.11$ & $24.06 \pm 2.4$ \\
$+0.3 \mathrm{mM} \mathrm{ADP}$ & $1.57 \pm 0.16$ & $0.88 \pm 0.06$ & $47.78 \pm 3.5$ \\
$+1 \mathrm{mM} \mathrm{KCN}$ & 0 & 0 & 0 \\
$+0.1 \mathrm{mM}$ Antimycin A & $0.38 \pm 0.05$ & $0.18 \pm 0.03$ & 0 \\
\hline
\end{tabular}

a Values are obtained from number of experiments as shown in parentheses (mean \pm S.D.).

${ }^{\mathrm{b}}$ Final concentration of each compound added into the reaction chamber are indicated.

c ADP was externally added three min after the addition of succinate into the reaction.

Table II. - Rate of oxygen consumption by asexual and sexual stages of P. falciparum and mouse liver mitochondria.

pectively. For comparison, the two enzymes in the organelles isolated from the asexual trophozoite stage were found to be $2.2 \pm 0.3(\mathrm{n}=6)$ for cytochrome $\mathrm{c}$ reductase and $2.8 \pm 0.6(n=6)$ for cytochrome c oxidase. The rate of oxygen consumption by isolated mitochondrial organelles was determined (Table II). It was found that the rate of oxygen consumption by both asexual and gametocytic stages was relatively low, comparing to the mammalian mitochondria. Nevertheless, their oxygen consumption were shown to be different, with the calculated values of $1.66 \pm 0.23$ $(\mathrm{n}=10)$ and $0.90 \pm 0.08(\mathrm{n}=6) \mathrm{nmol} / \mathrm{min} / \mathrm{mg}$ protein for asexual and gametocytic stages respectively. The mouse liver mitochondrial oxygen consumption was $\sim 15$ times higher than that of the parasite. When the oxygen consumption was performed in the infected erythrocytes harboring either asexual or sexual stages, they were not much different and had relatively low activities $\left(\sim 200-240 \mathrm{nmol} / \mathrm{min} / 10^{8}\right.$ parasites, $\left.\mathrm{n}=4\right)$, comparing to the human leukocytes which had an oxygen consumption of $1,100 \pm 50 \mathrm{nmol} / \mathrm{min} / 10^{8}$ cells $(n=3)$. $\mathrm{KCN}$, at $1 \mathrm{mM}$, had completely inhibitory effect against the oxygen consumption among asexual and sexual stages, mouse liver and human leukocytes. The asexual and sexual stages' mitochondrial oxygen consumption was found to be sensitive to antimycin A inhibition. At $0.1 \mathrm{mM}$ antimycin $\mathrm{A}$, it had $\sim 80 \%$ inhibitory effect in both stages mitochondria. However, the rate of oxygen consumption in the asexual and sexual stages was not stimulated by succinate and ADP, known substrates to support mitochondrial respiratory activity (Estrabrook, 1967). In contrast, the oxygen consumption of mitochondria from mouse liver was activated by both substrates with ADP:O ratio of $\sim 2$, since the amount of oxygen utilized was proportional to the amount of ADP phosphorylated to ATP when the mitochondria was state 3. (Table II). 


\section{DISCUSSION}

P falciparum undergoes growth and development into asexual and sexual blood stages in human erythrocytes. The metabolism and DNA, RNA, macromolecule synthesis in the asexual stage parasite have been extensively determined because of feasibility of the parasite obtained from the in vitro cultures developed by Trager \& Jensen (1976). The sexual gametocytic stage, maturing in the erythrocyte, is characterized by its ability to sequester in the microvascular of various organs, primarily the spleen and bone marrow. This phenomenon is thought to play a critical role in the development and survival of these gametocytes, which develop into gametes only in the mosquito midgut following ingestion during a blood meal. Based on the ultrastructural characteristics of the cultured sexual stages (Fig. 3), their mitochondria were found to be ultrastructurally different from those of the asexual blood stage (Fig. 2). This prompted us to study in detail the biochemical and molecular characterization of the mitochondrial organelles isolated from both developmental stages in human erythrocytes.

Although the triggers inducing gametocytogenesis of $P$. falciparum in host erythrocytes are not definitely known, e.g., use of alkaline $\mathrm{pH}$ media provided by bicarbonate ions (Ifediba \& Vanderberg, 1981), the appropriate amount of the gametocytes for the mitochondrial isolation has been obtained from the established culture of sexual blood stage (Petmitr \& Krungkrai, 1995; Krungkrai et al., 1999; Learngaramkul et al., 1999). The three different types of the mitochondria in these two stages have been reported based on the electron dense of matrices, numbers and appearances of tubular cristae structure (Krungkrai et al., 1999). The female gametocyte have more mitochondria (> 5 organelles) than the male gametocyte (Sinden, 1983; Krungkrai et al., 1999). Our results on the ultrastructural analysis have confirmed the existence of a stage variation in mitochondria, both in terms of their numbers and in the density of cristae. The phenomenon is well related to the fact in Haemogregarina myoxocephali, an apicomplexan blood parasite, that has different numbers of mitochondria in various developmental stages, i.e., 1-2 and 4-6 organelles for the asexual and sexual stages respectively (Siddall \& Desser, 1992). The mitochondrial organelles have been successfully isolated from the sexual gametocytic stage, as previously described in the asexual stage of $P$. falciparum (Fry \& Beesley, 1991; Krungkrai, 1995). The lines of evidence showing the morphologically and biochemically intact mitochondria are as follows: 1) they are well-defined double-membrane organelles having numerous tubular cristate structures which are originated from extensively infoldings of inner membrane
(Fig. 4A and B), as can be similarly observed in the whole parasite (Fig. 3); 2) they still maintain high membrane potential and have metabolically active, e.g., enzymatic activities of electron transporting complexes III \& IV, and oxygen consumption.

By comparison of the mitochondrial heterogeneous properties, e.g., differences in their morphological (Krungkrai et al.,1999) biochemical and genetic characteristics (Learngaramkul et al.,1999) in both asexual and gemetocytic stages, it is suggested that the metabolic activities of the gametocytic stages might be different from those of the asexual stages. However, the isolated organelles from both stages do not readily undergo activation of oxygen consumption upon the presence of externally added succinate and ADP. These results strongly indicate that the mitochondria from both stages are underdeveloped forms, existing in the uncoupling state and inactive for ATP production. In the asexual stage, the major pathways of carbohydrate metabolism are essentially anaerobic (Sherman, 1979; Scheibel et al., 1979; Scheibel, 1988), it would seem that the metabolism in the gametocytes are somewhat similar to the asexual stage parasites. In addition, our results also demonstrate a clear difference between the parasite and the mammalian mitochondria, the latter having a tight coupling oxidative phosphorylation for ATP production with $\mathrm{P}: \mathrm{O}$ ratio of $\sim 2$ in the presence of succinate and ADP (Table II).

In mitochondrion of the gametocyte, electron transport pathway may be similar to the asexual stage parasite in which electrons are transferred via ubiquinone and a series of cytochromes and oxygen is the final electron acceptor (Gutteridge et al., 1979; Krungkrai et al., 1991, 1993, 1997; Krungkrai, 1995). The mitochondrial electron transport system in both stages are sensitive to antimycin A and KCN (Table II), which are the specific inhibitors of complex III and IV respectively (Hatefi, 1985). Interestingly, these two inhibitors have been shown to inhibit not only the asexual growth (Ginsburg et al., 1986; Krungkrai et al.,1997) but also the purified enzymatic complexes III and IV (Krungkrai et al., 1997) of P. falciparum. Therefore, metabolic and physiological roles of the organelles with different morphological properties, e.g., heterogeneity, in the asexual and sexual stages of parasite development needs to be further studied.

\section{ACKNOWLEDGEMENTS}

his work was supported by the UNDP/World Bank/WHO Special Programme for Research and Training in Tropical Diseases and the National Science and Technology Development Agency of Thailand. 


\section{REFERENCES}

AiKawa M., Huff C.G. \& Sprinz H. Comparative feeding mechanisms of avian and primate malarial parasites. Military Medicine, 1966, 131, 969-983.

Airawa M. Plasmodium: the fine structure of malarial parasites. Experimental Parasitology, 1971, 30, 284-320.

Alano P. \& CARTER R. Sexual differentiation of malaria parasites. Annual Review of Microbiology, 1990, 44, 429-449.

BRADFORD M.M. A rapid and sensitive method for the quantitation of microgram quantities of protein utilizing the principle of protein-dye binding. Analytical Biochemistry, 1976, 72, 248-254.

De Rojas M.O. \& Wasserman M. Temporal relationships on macromolecular synthesis during the asexual cell cycle of Plasmodium falciparum. Transactions of the Royal Society of Tropical Medicine and Hygiene, 1985, 79, 792-796.

ESTRABROOK R.W. Mitochondrial respiratory control and the polaragraphic measurement of ADP:O ratios. Methods in Enzymology, 1967, 10, 41-47.

FEAGIN J.E. \& DREw M.E. Plasmodium falciparum : Alterations in organelle transcript abundance during the erythrocytic cycle. Experimental Parasitology, 1995, 80, 430-440.

Fry M. \& BeEsley J. E. Mitochondria of mammalian Plasmodium spp. Parasitology, 1991, 102, 17-26.

FRY M. \& PUDNEY M. Site of action of the antimalarial hydroxynaphoquinone, 2-[trans-4-(4'-chlorphenyl)cyclohexyl]3-hydroxy-1,4-naphthoquinone (566C80). Biochemical Pharmacology, 1992, 43, 1545-1553.

Ginsburg H., Divo A. A., Geary T.G., Boland M.T. \& Jensen J. B. Effect of mitochondrial inhibitors on intraerythrocytic Plasmodium falciparum in in vitro cultures. Journal of Protozoology, 1986, 33, 121-125.

Gutteridge W.E., Dave D. \& Richards W.H.G. Conversion of dihydroorotate to orotate in parasitic protozoa. Biochimica et Biophysica Acta, 1979, 582, 390-401.

Hatefi Y. The mitochondrial electron transport and oxidative phosphorylation system. Annual Review of Biochemistry, 1985, 54, 1015-1069.

Hawking F., Wilson M. E. \& Gammage K. Evidence for cyclic development and short-lived maturity in the gametocytes of Plasmodium falciparum. Transactions of the Royal Society of Tropical Medicine and Hygiene, 1971, 65, 549559.

IFEDiBa T. \& VANDERBERG J.P. Complete in vitro maturation of Plasmodium falciparum gametocytes. Nature, 1981, 294, 364-366

INSELBURG J. \& BANYAL H.S. Synthesis of DNA during the asexual of Plasmodium falciparum in culture. Molecular and Biochemical Parasitology, 1984, 10, 79-87.

Kawai S., Kano S. \& Suzuki M. Morphologic effects of artemether on Plasmodium falciparum in Aotus Trivirgatus. The American Journal of Tropical Medicine and Hygiene, 1993, 49, 812-818.

KNIGHT A. \& Sinden R.E. The purification of gametocytes of Plasmodium falciparum and $P$. yoelii nigeriensis by colloidal silica (Percoll) gradient centrifugation. Transactions of the Royal Society of Tropical Medicine and Hygiene, 1982, 76, 503-509.

Krungkrai J., Cerami A. \& Henderson G.B. Purification and characterization of dihydroorotate dehydrogenase from the rodent malaria parasite Plasmodium berghei. Biochemistry, 1991, 30, 1934-1939.

Krungkrai J., Krungkrai S.R. \& Bhumiratana A. Plasmodium berghei: partial purification and characterization of the mitochondrial cytochrome c oxidase. Experimental Parasitology, 1993, 77, 136-146.

KRUNGKRAI J. Purification, characterization and localization of mitochondrial dihydroorotate dehydrogenase in Plasmodium falciparum, human malaria parasite. Biochimica et Biophysica Acta,1995, 1243, 351-360.

Krungkrai J., Krungkrai S. R., Suraveratum, N. \& PrapunWATTANA P. Mitochondrial ubiquinol-cytochrome $\mathrm{c}$ reductase and cytochrome c oxidase: chemotherapeutic targets in malarial parasites. Biochemistry and Molecular Biology International, 1997, 42, 1007-1014.

Krungkrai S.R., Learngaramkul P., Kudan S., Prapunwattana P. \& Krungkrai J. Mitochondrial heterogeneity in human malarial parasite Plasmodium falciparum. Science Asia, 1999, 25, 77-83.

LAMBros C. \& VANDERBERG J.P. Synchronization of Plasmodium falciparum erythrocytic stages in culture. Journal of Parasitology, 1979, 65, 418-420.

Langreth S.G., Jensen J.B., Reese R.T. \& Trager W. Fine structure of human malaria in vitro. Journal of Protozoology, 1978, 25, 443-452.

LANNERS H.N. Effect of the 8-aminoquinoline primaquine on culture-derived gametocytes of the malaria parasite Plasmodium falciparum. Parasitology Research, 1991, 77, 478481.

Learngaramkul P., Petmitr S., Krungkrai S.R., Prapunwattana P. \& Krungkrai J. Molecular characterization of mitochondria in asexual and sexual blood stages of Plasmodium falciparum. Molecular Cell Biology Research Communications, 1999, 2, 15-20.

Lobo C.A. \& Kumar N. Sexual differentiation and development in the malaria parasite. Parasitology Today, 1998, 14, 146-150.

Petmitr S. \& Krungkrai J. Mitochondrial cytochrome b gene in two developmental stages of human malarial parasite Plasmodium falciparum. Southeast Asian Journal of Tropical Medicine and Public Health, 1995, 26, 600-605.

Prapunwattana P., O'Sullivan W.J. \& Yuthavong Y. Depression of Plasmodium falciparum dihydroorotate dehydrogenase activity in in vitro culture by tetracycline. Molecular and Biochemical Parasitology, 1988, 27, 119-124.

RichWOOD D., WiLSON M.T. \& DARLEY-Usmar V.M. Isolation and characteristics of intact mitochondria, in: Mitochondria; A practical approach. Darley-Usmar V.M., Rickwood D. \& Wilson M.T. (eds), IRL Press, Oxford, 1987, 1-16.

Robinson J. \& COOPER J.M. Method of determining oxygen concentrations in biological media, suitable for calibration of the oxygen electrode. Analytical Biochemistry, 1970, 33, 390-399. 
Scheibel L.W., Ashton H.S. \& Trager W. Plasmodium falciparum: Microaerophillic requirements in human red blood cells. Experimental Parasitology, 1979, 47, 410-418.

Scheibel L.W. Plasmodial metabolism: carbohydrate, in: Malaria. Wernsdorfer W.H. \& McGregor I. (eds), Churchill Livingstone, New York, 1988, vol. I, 171-217.

SHERman I.W. Biochemistry of Plasmodium (malaria parasites). Microbiological Reviews, 1979, 43, 453-495.

SIDDALL M.E. \& DESSER S.S. Ultrastructure of gametogenesis and sporogony of Haemogregarina (sensu lato) myoxocephali (Apicomplexa: Adeleina) in the marine leech Malmiana scorpii. Journal of Protozoology, 1992, 39, 545-554.

Sinden R.E. \& SMAlley M.E. Gametocytogenesis of Plasmodium falciparum in vitro: the cell-cycle. Parasitology, 1979, 79, 277-296.

SINDEN R.E. Gametocytogenesis of Plasmodium falciparum in vitro: an electron microscopic study. Parasitology, 1982, 84, 1-11.

Sinden R.E. Sexual development of malarial parasites. Advance in Parasitology, 1983, 22, 154-216.

Srivastava I.K., Rottenberg H. \& Vaidya A.B. Atovaquone, a broad spectrum antiparasitic drug, collapses mitochondrial membrane potential in a malarial parasite. The Journal of Biological Chemistry, 1997, 272, 3961-3966.

Trager W. \& Jensen J.B. Human malaria parasites in continuous culture. Science, 1976, 193, 673-675.

Trigg P.I. Plasmodiidae, in: Methods of Culturing Parasites in vitro. Taylor A.E.R. \& Baker J.R., (eds), Academic Press, London, 1978, 89-100.

Vaidya A.B., Lashgari M.S., Pologe L.G. \& Morrisey J. Structural features of Plasmodium cytochrome $\mathrm{b}$ that may underline susceptibility to 8-aminoquinolines and hydroxynaphthoquinones. Molecular and Biochemical Parasito$\log y, 1993,58,33-42$.

Reçu le 28 octobre 1999

Accepté le 4 janvier 2000 